\title{
A nurse-managed population based heart failure clinic: sustaining quality of life
}

\author{
Lucille Travis, Sonya R. Hardin, Zeleka G. Benton, Leigh Austin, Laura W. Norris \\ School of Nursing, University of North Carolina, Charlotte, United States
}

Correspondence: Lucille Travis. Address: 9201 University City Boulevard, Charlotte, NC 28223. Telephone: 704-687-7959. Email: Ltravis@uncc.edu

Received: February 20, 2012

Accepted: March 15, 2012

Published: November 1, 2012

DOI : $10.5430 /$ jnep.v2n4p1

URL: http://dx.doi.org/10.5430/jnep.v2n4p1

\section{Abstract}

Background: Heart failure (HF) affects approximately 5.8 million people in the US. Each year an additional 670,000 new cases of HF are diagnosed and about 300,000 people die. HF is one of the most common reasons for hospitalization, especially in those over age 65 , and it accounts for about $\$ 39.2$ billion dollars in health care costs. The cost of inpatient care and the many treatment options available have led to the development of population based managed care (PBMC) HF clinics. Managed care most commonly occurs in outpatient settings, but there is relatively little data on the effectiveness of nurse-managed population based managed care (PBMC) in improving outcomes. The aim of this study was to examine the quality of life (QOL) of outpatient HF patients $(\mathrm{N}=80)$ who used a nurse-managed PBMC heart failure clinic in a southern urban US city.

Methods: This was a correlational descriptive study. Data were collected at baseline, 6 months, and 12 months using Short Form (SF)-12 assessments.

Results: Findings showed subjects were able to maintain their mental and physical status even though it would ordinarily be expected to decline over time.

Conclusions: Use of nurse-managed PBMC heart failure clinics has value in sustaining QOL for patients and should be considered as a useful approach for maintaining patient physical and mental function.

\section{Key words}

Heart failure, Disease management programs, Population based managed care

\section{I ntroduction}

Heart failure (HF) is a chronic, serious, and expensive medical condition affecting approximately 5.8 million people in the United States. Heart failure is the only cardiovascular disorder that is increasing in both incidence and prevalence in the U.S. Each year an additional 670,000 new cases of HF are diagnosed ${ }^{[1]}$. Survival after HF diagnosis has improved over time. However, the death rate remains high; one in five individuals will die within one year of the diagnosis and $50 \%$ of people diagnosed with HF will die within 5 years. This devastating disease in people is a major cause of debilitating symptoms, frequent rehospitalizations, and high rates of mortality in those over age $65^{[1,2]}$. HF is one of the most common reasons for hospitalization, and indeed, it is estimated that heart failure accounts for approximately $25 \%$ of all cardiac admissions. In 2010, heart failure resulted in an estimated cost of $\$ 39.2$ billion for the United States. These figures 
represent the financial resources required to address needs relating to health care services, medications and lost productivity. Hospital readmissions due to HF exacerbations have become a persistent problem, and in part are responsible for the escalating costs to the U.S. health care system ${ }^{[1,2,4]}$.

A key problem for patients with HF is quality of life. Patients must track their daily symptoms, dietary choices, and weight, and adhere to medication regimens in order to maintain health. The pathology of chronic heart failure leads to symptoms such as shortness of breath at rest, shortness of breath on exertion, and fatigue, which can then lead to limitations in activities of daily living and work-related activities. Office visit co-pays, hospital co-insurance, and medication costs may lead to financial distress. Physiologic symptoms, treatment side effects or financial distress may lead to psychological distress. Rector, Anand, and Cohn ${ }^{[5]}$ found that ordinary symptoms of heart failure were the causes of "approximately $40 \%$ of the variation in quality of life." It may thus be argued that symptoms of heart failure are crucial influences on people's quality of life. Patients' ability to actively manage their own care also affects their quality of life.

However, most heart failure patients do not understand their disease process, nor do they comply with appropriate treatment regimens ${ }^{[6,7]}$. Hence, there is a need for heart failure management programs that encompass components described by the Consensus Statement of the Heart Failure Society of America. These components are disease management, functional assessment, quality of life assessment, medical therapy and drug evaluation, device evaluation, nutritional assessment, follow-up, advance planning, communication, provider education, and quality assessment ${ }^{[4]}$.

The literature has shown that participation in heart failure disease management programs is associated with improved clinical outcomes as well as quality of life ${ }^{[6-8]}$. Patients who participate in a disease management program have been found to experience significant survival benefits by increasing appropriate medication prescriptions, improving treatment compliance, and reducing hospitalizations ${ }^{[4,10,11]}$. In addition to reduced hospitalizations, heart failure disease management programs have improved mortality for heart failure patients by an amount similar to that achieved by drug therapy ${ }^{[6]}$.

"Population based managed care is an approach to planning and delivering care to defined patient population that tries to ensure that effective interventions reach all patients who need them" ${ }^{[12]}$. In an HF population-based managed care (PBMC) approach, an advanced practice nurse, an expert nurse clinician, works in collaboration with members of a multidisciplinary team that may include "physicians, nurses, pharmacists, nutritionists, social workers, exercise physiologists, and other health care professionals with specialized training and skills in HF management" ${ }^{\text {[4] }}$ to deliver effective services, maximize health outcomes and lower costs. It is widely recognized that outpatient disease management programs improve clinical and hospital outcomes, but there is relatively little data on the effectiveness of nurse-managed population based managed care (PBMC) in improving outcomes of patients with heart failure. However, several studies have found that multidisciplinary teams for the management of patients with heart failure improved outcomes for patients ${ }^{[13-15]}$. The goals of multidisciplinary heart failure management programs are to reduce mortality and rehospitalization rates and improve quality of life for patients through individualized patient care ${ }^{[4]}$.

Quality of life has been found to be a predictor of outcomes in heart failure patients managed in a disease management program ${ }^{[14,16,17]}$. Health related quality of life is defined as "aspects of an individual's subjective experience that relate both directly and indirectly to health, disease, disability, and impairment" ${ }^{[18]}$. The purpose of this study was to examine the quality of life of outpatient HF patients who used a nurse-managed population based managed care (PBMC) heart failure clinic over time.

\section{Method}

This correlational descriptive study was approved by the university IRB. Patients enrolled in the program signed an informed consent upon entry into the disease management program. Quality of life surveys were administered to patients by trained heart failure clinic staff. Patients were not approached by the investigators, and no patient identifying data were 
collected. Only the patient's New York Heart Association (NYHA) classification, age, race, gender and responses to questions on the quality of life questionnaire were recorded.

\subsection{Setting}

The study was conducted in a nurse-managed disease management program located in an urban area in the South. The program provides education, treatment and management to heart failure patients. The heart failure clinic team consists of a nurse practitioner, expert nurse clinician, and dietitian, along with a social worker and resource specialist; the team uses evidenced based practice interventions. The advanced practice nurse and expert nurse clinician work in collaboration with other team members to maximize health outcomes and lower costs. The resource specialist assists patients to find services to help cover the costs of medications, and the social worker helps to integrate other ancillary services needed to ensure quality of care. The dietitian provides nutritional recommendations and counseling as warranted.

\subsection{Sample}

A convenient sample of 80 heart failure patients enrolled in the nurse-managed outpatient clinic completed the survey at three time points. The heart failure clinic instituted the use of the SF-12 survey as part of their normal protocol to measure quality of life. Each time a patient came to the clinic, a SF-12 survey is completed as part of the regular work up. This practice is one of the components of a heart failure clinic described by the Consensus Statement on Heart Failure Clinics ${ }^{[2]}$. The sample in this study included men $(n=48)$ and women $(n=32)$; they were Caucasian $(n=46)$, African-American $(n=33)$ or other $(n=1)$, and ranged in age from 28-96 years old with a mean age of 71.07. The New York Heart Association (NYHA) classification, which is most frequently used to describe patients' functional capacity, was used to establish heart failure stage. NYHA classifications are defined as follows: Class I-no symptoms with ordinary activity; Class II-no symptoms at rest (ordinary activity results in symptoms); Class III-less than ordinary activity causes symptoms (no symptoms at rest); Class IV-symptoms at rest. The patients' NYHA classification was determined by the nurse practitioner. The sample included individuals with Stage II $(n=15)$, Stage III $(n=52)$ and Stage IV ( $n=13)$ heart failure. Table 1 displays the demographics of the sample.

Table 1. Demographic Characteristics of Sample $(\mathrm{N}=80)$

\begin{tabular}{|c|c|c|}
\hline Characteristics & $\mathbf{n}$ & Percent \\
\hline \multicolumn{3}{|l|}{ Gender } \\
\hline - Male & 48 & $60.0 \%$ \\
\hline - Female & 32 & $40.0 \%$ \\
\hline \multicolumn{3}{|l|}{ Race } \\
\hline - Caucasian & 46 & $57.5 \%$ \\
\hline - African-American & 33 & $41.3 \%$ \\
\hline - Unknown & 1 & $1.2 \%$ \\
\hline \multicolumn{3}{|c|}{ New York Heart Failure Classification (NYHA) } \\
\hline - I & 0 & $0 \%$ \\
\hline - $\quad$ II & 15 & $18.8 \%$ \\
\hline - $\quad$ III & 52 & $65.0 \%$ \\
\hline - IV & 13 & $16.2 \%$ \\
\hline
\end{tabular}

\subsection{I nstruments}

The SF 12, a short-form health survey with 12 questions, was used to assess quality of life. The SF 12 measures general health status from the patient's point of view. The survey includes physical functioning, role functioning physical, bodily pain, general health, vitality, social functioning, role functioning emotional, and mental health. Results are expressed in 
two meta-scores: the Physical Component Summary (PCS) and the Mental Component Summary (MCS). High scores indicate better functioning and quality of life. The PCS and MCS scores have a range from 0-100 with a mean score of 50 representing the average health status of the general US population ${ }^{[19]}$. The validity and reliability of the SF 12 are well established; and it has been found to be a satisfactory tool for monitoring overall physical and mental health outcomes ${ }^{[20]}$. Reliabilities have ranged from 0.91 to 0.92 . Validity scores for the 12-item Physical Component Summary have ranged from 0.43 to 0.93 (median=0.67) and the validity scores for the 12-item Mental Component Summary have ranged from 0.60 to 107 (median=0.97) ${ }^{[21]}$.

\section{Results}

The means of the PCS and MCS were calculated for a total average over the three time points. The average score over these time points was 32.77 for the PCS and 49.95 for the MCS (see Table 2). These scores are of particular interest given that the population mean is 50 . To evaluate change in quality of life, a $t$-test was performed to look at differences in PCS and MCS scores from Time 1 to Time 3. No significant change was noted. The mean PCS at Time 1 was 30.89 and at Time 3 it was 34.14. The mean MCS at Time 1 was 48.59 and at Time 3 was 50.07. There was no significant decline for PSC or MCS across time. However, clinically this is significant as stabilization of scores can be seen over 12 months (see Table 3). Figure 1 shows the trends in PCS and MCS scores from baseline to 6 and 12 months. There were no significant differences between races on the PCS or MCS at baseline or 6 and 12 months. However, the average scores on the PCS and MCS scores were higher for Black patients (see Table 4). An ANOVA was performed to test for differences between males and females on PCS and MCS at baseline, and at 6 and 12 months. There was no significant difference between gender on PCS and MCS at a significance of .05. Figure 2 provides PCS and MCS score means of men and women at each time point. Table 5 shows the slow decline of MCS and PCS scores between stages 2 and 3. However, MCS and PCS scores were stable between stages 3 and 4 .

Table 2. Mean, Median, Range of PCS and MCS Scores

\begin{tabular}{llll}
\hline Item & & PCS & MCS \\
\hline $\mathrm{N}$ & Valid & 80 & 80 \\
& Missing & 0 & 0 \\
Mean & & 32.7729 & 49.9517 \\
Median & 32.8000 & 50.4500 \\
Std. Deviation & 9.42027 & 10.31398 \\
Minimum & 10.60 & 18.90 \\
Maximum & 60.60 & 71.20 \\
\hline
\end{tabular}

Table 3. Difference in PCS Scores and MCS Scores from Time 1 to Time 3

\begin{tabular}{lllllll}
\hline & Time & N & Mean & Std. Deviation & Std. Error Mean & T-Test \\
\hline \multirow{2}{*}{ PCS } & 1.00 & 80 & 30.8912 & 8.81606 & .98566 & Sig. level 0.638 \\
& 3.00 & 80 & 34.1450 & 9.55058 & 1.06779 & \\
MCS & 1.00 & 80 & 48.5925 & 11.2813 & 1.26136 & Sig . level 0.0858 \\
& 3.00 & 80 & 50.0750 & 9.10786 & 1.01829 & \\
\hline
\end{tabular}

Note. $p<0.05$ 
A multivariate test was conducted to examine the effects of age on physical and mental scores at each time period (see Table 6). There was a significant difference in PCS and MCS scores between subjects aged 28-69 and those older than 70. These tests controlled for the covariates of NYHA stage and time. Reliability of the SF-12 survey was .540 at baseline, .520 at 6 months and .486 at 12 months. The reliability was stable over time in this study. However, given the small sample size, further studies would need to be conducted to examine other confounding variables which could help explain difference in PCS and MCS with age.

Table 4. Difference in Race PCS and MCS between Races

\begin{tabular}{lllllll}
\hline \multirow{2}{*}{ MCS } & Race & N & Mean & Std. Deviation & Std. Error Mean & Significance \\
& white & 46 & 49.7891 & 10.16952 & .86569 & NS \\
\multirow{2}{*}{ PCS } & black & 33 & 50.2162 & 10.35950 & 1.04117 & NS \\
& white & 46 & 31.5196 & 8.95351 & .76217 & .96885 \\
\hline
\end{tabular}

Note. $p<0.05$

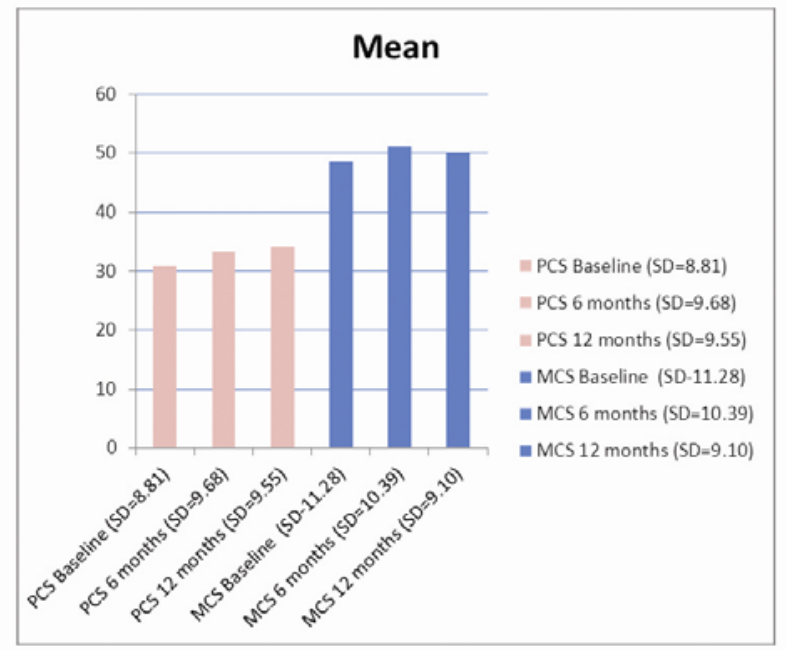

Figure 1. Mean and SD PCS and MCS scores at Baseline, 6 and 12 Months

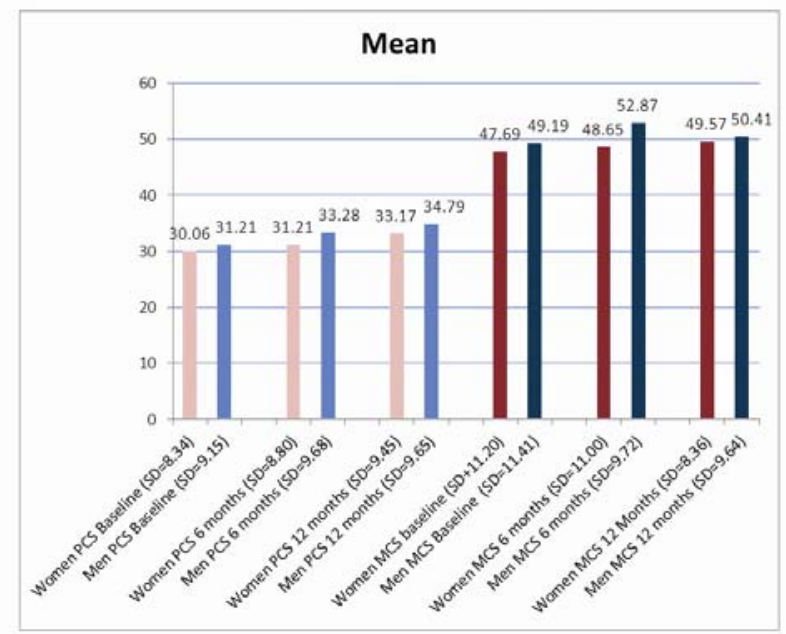

Figure 2. Differences between Men and Women at Baseline, 6 and 12 months (this description needs to be attached to the above Figure 2) 
Table 5. Mean Scores and SD per Heart Failure Stage

\begin{tabular}{llll}
\hline & Stage $2 \bar{x}(\mathbf{s d})$ & Stage $\mathbf{3}(\mathbf{x})$ & Stage $\mathbf{4} \bar{x}(\mathbf{s d})$ \\
\hline PCS & $35.81(8.70)$ & $32.06(9.34)$ & $32.10(10.01)$ \\
MCS & $51.59(10.62)$ & $49.52(10.53)$ & $49.75(9.05)$ \\
\hline
\end{tabular}

Table 6. Multivariate Tests of between Subjects Effects

\begin{tabular}{|c|c|c|c|c|c|c|}
\hline Source & $\begin{array}{l}\text { Dependent } \\
\text { Variable }\end{array}$ & Type III Sum of Squares & df & Mean Square & $\mathbf{F}$ & Sig. \\
\hline \multirow{2}{*}{ Corrected Model } & PCS & $8350.905^{\mathrm{a}}$ & 55 & 151.835 & 2.173 & $.000 * *$ \\
\hline & MCS & $12234.001^{\mathrm{b}}$ & 55 & 222.436 & 3.103 & $.000 * *$ \\
\hline \multirow{2}{*}{ Intercept } & PCS & 28177.253 & 1 & 28177.253 & 403.211 & $.000 * *$ \\
\hline & MCS & 74432.579 & 1 & 74432.579 & 1038.302 & $.000 * *$ \\
\hline \multirow{2}{*}{ Time } & PCS & 423.476 & 1 & 423.476 & 6.060 & $.015^{* *}$ \\
\hline & MCS & 87.912 & 1 & 87.912 & 1.226 & .270 \\
\hline \multirow{2}{*}{ NYHA } & PCS & 366.632 & 2 & 183.316 & 2.623 & .075 \\
\hline & MCS & 160.222 & 2 & 80.111 & 1.118 & .329 \\
\hline Age Category & PCS & 5032.178 & 39 & 129.030 & 1.846 & $.004 *$ \\
\hline$\leq 69$ or $\geq 70$ & MCS & 6702.698 & 39 & 171.864 & 2.397 & $.000 * *$ \\
\hline \multirow{2}{*}{ NYHA * Age } & PCS & 1920.875 & 13 & 147.760 & 2.114 & $.015 *$ \\
\hline & MCS & 4257.932 & 13 & 327.533 & 4.569 & $.000 * *$ \\
\hline \multirow{2}{*}{ Error } & PCS & 12858.329 & 184 & 69.882 & & \\
\hline & MCS & 13190.378 & 184 & 71.687 & & \\
\hline \multirow{2}{*}{ Total } & PCS & 278984.610 & 240 & & & \\
\hline & MCS & 624264.940 & 240 & & & \\
\hline \multirow{2}{*}{ Corrected Total } & PCS & 21209.234 & 239 & & & \\
\hline & MCS & 25424.379 & 239 & & & \\
\hline
\end{tabular}

${ }^{*} p<.05 ;{ }^{* *} p<.001$

\section{Discussion}

An abundance of research has noted that heart failure disease management programs lead to improvements in health related patient outcomes, including a decrease in hospitalizations and mortality and improvements in quality of life ${ }^{[4,6,7,9,14-16]}$. It is commonly accepted that outpatient disease management programs improve both clinical and hospital outcomes, but there is relatively little data on the effectiveness of nurse-managed population based managed care (PBMC) in improving QOL of patients with heart failure.

These data suggest that nurse-managed PBMC heart failure clinics helped to maintain quality of life in heart failure patients over a 12-month period. Nonetheless, the findings showed a stable trend in PCS, and over the 12 months, participants had PCS scores well below those of the general US health population. MCS scores were at the average score for the US population and essentially were maintained over 12 months of participation in the heart failure disease management program.

Black subjects reported higher MCS and PCS scores. This would indicate a higher perceived quality of life with heart failure. However this is in contrast with reported literature ${ }^{[22,23]}$. These early studies may not be consistent with the present data due to associating early onset of heart failure, poor functional out comes and lack of health care processes within facilities. Consistent with the evidence reported by Singer and Ryff ${ }^{[24]}$ and Elder and Crosnoe ${ }^{[25]}$, the biopsychosocial model of cumulative psychological vulnerability and resistance in life model therefore hypothesizes that it is the balance 
between cumulative adversities or vulnerabilities and cumulative advantages or assets over the life-course and the life transitions experienced that ultimately contributes to differences in functional status and health trajectories in the elderly, both overall and as a function of ethnicity, gender, and social class ${ }^{[26]}$. Given this model, the ability of blacks to perceive a higher quality of life could be due to past life experiences with adversity resulting in a higher level of resilience ${ }^{\text {[27] }}$.

Men have higher incident rates of heart failure and poor survival compared to women. Women appear to gain heart failure at an older age ${ }^{[28]}$. Some studies have reported that women had worse QOL scores than men for intermediate activities of daily living and social activity ${ }^{[29]}$. In this study there was no significant difference between gender on PCS and MCS. This could be due to small numbers; however, we had a higher percentage of older subjects than most studies. Elderly black patient may have a survival advantage compared with elderly white patients according to Rathore ${ }^{[27]}$.

There was a significant difference between those under age 70 and those over 70 on PCS and MCS scores. This finding is similar to those reported over the age of 60 with heart failure having only 2 or fewer criteria for the Ideal Cardiovascular Health Profile ${ }^{[2]}$. These criteria include smoking, BMI, physical activity, diet, total cholesterol, blood pressure and resting plasma glucose. Adults over the age of 60 were more likely to meet the physical activity and diet criteria ${ }^{[2]}$ for an ideal Cardiovascular Health Profile

The examination of older adults with heart failure has not been prevalent in the literature due to many studies having upper age limits, hence age disparity exists. Recommendations for having NIH require investigators to insist on recruitment plans to enroll persons in age ranges relative to the prevalence of heart failure in the general population would enhance our understanding of the aging experience. The physical, sensory and cognitive impairments common in older adults can be overcome with reasonable accommodations, including large-font informed consent documents, hearing assistance, improved accessibility to study sites, transportation to study visits and provision for targeted home visits ${ }^{[30]}$.

This study data showed a slow decline of MCS and PCS scores between stages 2 and 3. However, MCS and PCS scores were stable between stages 3 and 4. This is similar data reported by Westlake, et al. that NYHA classification has been found to be related to the physical component of quality of life ${ }^{[31]}$.

This analysis of SF-12 quality of life surveys in 80 heart failure patients enrolled in a nurse-managed disease management program in an urban region shows the benefits that nurse-managed heart failure disease management programs have for quality of life in patients afflicted with this debilitating and devastating disease. However, given the small sample of 80 subjects and lack of randomization, generalization of the study is limited. While changes across time were minimal here, a larger sample size could possibly yield significant differences.

Despite these limitations, these study results provide evidence to support the use of nurse-managed disease management programs for heart failure patients to improve both health related outcomes and quality of life. Such programs have been found to reduce hospital admissions, emergency room visits, hospital days and improve quality of life ${ }^{[32,33]}$.

\section{References}

[1] Lloyd-Jones D, Adams RJ, Brown TM, et al. Heart disease and stroke statistics 2010 update: A report from the American Heart Association. Circulation. 2010; 121: e46-e215. PMid:20019324 http://dx.doi.org/10.1161/CIRCULATIONAHA.109.192667

[2] Roger, $\mathrm{V}$ et al. Heart disease and stroke statistics-2011 update: a report from the American Heart Association statistics committee and stroke statistics subcommittee Circulation [Internet]. 2011; 123: e1-e193. Available from:

http://circ.ahajournals.org/content/early/2010/12/15/CIR.0b013e3182009701.citation. Downloaded from http://circ.ahajournals.org/ by guest on December 22, 2011 DOI: 10.1161/CIR.0b013e3182009701 (volume 4)

[3] Maeda JLK. Evidence-based heart failure performance measures and clinical outcomes: A systematic review. Journal of Cardiac Failure. 2010; 16(5): 411-418. PMid:20447578 http://dx.doi.org/10.1016/j.cardfail.2010.01.005 
[4] Hauptman, P., Rich, M., Heidenreich, P., Chin, J., Cummings, N., Dunlap, M., Edwards, M., Gregory, D., O’Connor, C., Pezzella, S., \& Philbin, E. The Heart Failure Clinic: A Consensus Statement of the Heart Failure Society of America. Journal of Cardiac Failure. 2008; 14 (10): 801-815. PMid:19041043 http://dx.doi.org/10.1016/j.cardfail.2008.10.005

[5] Rector TS, Anand IS, Cohn JN. Relationships between clinical assessments and patients' perceptions of the effects of heart failure on their quality of life. Journal of Cardiac Failure. 2006; 12(2): 87-92. PMid:16520254 http://dx.doi.org/10.1016/j.cardfail.2005.10.002

[6] Arday, D., Dall, T., Gantt, C., Wagner, R., Yang, W., Zhang, Y. Outcomes and lessons learned from evaluating TRICARE's disease management programs. The American Journal of Managed Care. 2010; 16(6): 438-446. PMid:20560687

[7] Chan, D.C., Heidenreich, P.A., Weinstein, M.C., Fonarow, G.C. Heart failure disease management programs: a cost-effectiveness analysis. American Heart Journal. 2008; 155(2): 332-338. PMid:18215605 http://dx.doi.org/10.1016/j.ahj.2007.10.001

[8] Cruz, F., Issa, V., Ayub-Ferreira, S., Chizzola, P., Souza, C.,Moreira, L., Lanz-Luces, et al. Effect of a sequential education and monitoring programme on quality-of-life components in heart failure. European Journal of Heart Failure. 2010; 12: $1009-1015$. PMid:20670963 http://dx.doi.org/10.1093/eurjhf/hfq130

[9] Iqbal, J., Francis, L., Reid, J., Murray, S., Denvir, M. Quality of life with patients with chronic heart failure and their careers: a 3 year follow up study assessing hospitalization and mortality. European Journal of Heart Failure. 2010; 12(9): 1002-1008. PMid:20615920 http://dx.doi.org/10.1093/eurjhf/hfq114

[10] Laederach-Hoffmann, K., Rohrer-Gilbeli, R., Messerli, N., Meryer, K. Comprehensive rehabilitation in chronic heart failure Better psycho-emotional status related to quality of life, brain natriuretic peptide concentrations, and clinical severity of disease. Clinical and Investigative Medicine. 2007; 30 (2): E54-E62. PMid:17716542

[11] O'Loughlin C, Murphy NF, Cronlon C, O’Donovan A, Ledwidge, McDonald K. Quality of life predicts outcomes in a heart failure disease management program. International Journal of Cardiology. 2010; 139(1): 60-67. PMid:18851887 http://dx.doi.org/10.1016/j.ijcard.2008.09.003

[12] Wagner, E. The role of patient care teams in chronic disease management. BMJ. 2000; 320; 569-572. PMid:10688568 http://dx.doi.org/10.1136/bmj.320.7234.569

[13] Flynn, K., Lin, L., Ellis, S., Russell, S., Spertus, J., Whellan, D.,et al. Outcomes, health policy, and managed care: Relationships between patient-reported outcome measures and clinical measures in outpatients with heart failure. American Heart Journal. 2009; 158 (4): 564-571. PMid:19782791 http://dx.doi.org/10.1016/j.ahj.2009.07.010

[14] Feldman, D., Ducharme, A., Giannetti, N., Frenette, M., Michel, C., Grondin, F., et al. Outcomes for women and men who attend a heart failure clinic: Results of a 12-month longitudinal study. Journal of Cardiac Failure. 2011; 17 (7): 540-546. PMid:21703525 http://dx.doi.org/10.1016/j.cardfail.2011.03.001

[15] Lin, A., Cavendish, J., Boren, D., Ofstad, T., Seidensticker, D. A pilot study: Reports of benefits from a 6-month, multidisciplinary, shared medical appointment approach for heart failure patients. Military Medicine. 2008; 173 (12): 1210-1213. PMid:19149341

[16] Hole, Torstein, Grundtvig, Morten, Gullestad, Lars, Flønæs, Berit, Westheim, Arne. Improved quality of life in Norwegian heart failure patients after follow-up in outpatient heart failure clinics: results from the Norwegian heart failure registry European Journal of Heart Failure. 2010; 12: 1247-1252. PMid:20847014 http://dx.doi.org/10.1093/eurjhf/hfq156

[17] Zuluaga, Maria Clemencia, Guallar-Castillo'n, Pilar, pez-Garcı'a, Esther Lo' , Banegas, Jose' R., Conde-Herrera, Manuel, Olcoz-Chiva, Maite, Rodri'guez-Pascual, Carlos, and Rodriguez-Artalejo, Fernando. Generic and disease-specific quality of life as a predictor of long-term mortality in heart failure European Journal of Heart Failure. 2010; 12: 1372-1378. PMid:20861126 http://dx.doi.org/10.1093/eurjhf/hfq163

[18] Carr AJ, Gibson B, Robinson PG. Measuring quality of life. BMJ. 2001; 322: 1240-1243. PMid:11358783 http://dx.doi.org/10.1136/bmj.322.7296.1240

[19] Quality Metric (n.d.). The SF 12: An even shorter health survey. Retrieved March 1, 2010. Available from: http://www.sf-36.org/tools/sf12.shtml

[20] Ware, J.E., Kosinski, M., \& Keller, S.D. A 12-item short-form healthy survey: Construction of scales and preliminary tests of reliability and validity. Medical Care. 1996; 34(3): 220-233. PMid:8628042 http://dx.doi.org/10.1097/00005650-199603000-00003

[21] Melville, M.R., Lari, M.A., Brown, N., Young, T., Gray, D. Quality of life assessment using the short form 12 questionnaire is as reliable and sensitive as the short form 36 in distinguishing symptom severity in myocardial infarction survivors. Heart. 2008; 89: 1445-1446. PMid:14617561 http://dx.doi.org/10.1136/heart.89.12.1445

[22] Vaccarino, V., Gahbauer E., Kasl SV, Charpentier PA, Acampora D, Krumholz HA. Differences between African Americans and whites in the outcome of heart failure: Evidence for a greater functional decline in African Americans. Am Heart J. $2002 ; 143$ (6): 1058-67. PMid:12075264 http://dx.doi.org/10.1067/mhj.2002.122123 
[23] Philbin, EF, DiSalvo, TG. Influence of race and gender on care process, resource use and hospital based outcomes in congestive heart failure. Am J Cardiol. 1998; 82: 76-81. http://dx.doi.org/10.1016/S0002-9149(98)00233-1

[24] Singer B, Ryff, CD. Hierarchies of life histories and associated health risks. In: Adler NE, Marmot M, McEwen BS, Stewart J, editors. Socioeconomic status and health in industrial nations: Social, psychological, and biological pathways. New York: New York Academy of Sciences. 1999; 96-115.

[25] Elder GH Jr, Crosnoe R. The influence of early behavior patterns on later life. In: Pulkkinen L, Caspi A, editors. Paths to successful development: Personality in the life course. New York: Cambridge University Press. 2002; 157-176. http://dx.doi.org/10.1017/CBO9780511489761.007

[26] Myers, H.F., Hwang, W-C. Cumulative psychosocial risks \& resilience: A conceptual perspective on ethnic health disparities in late life. In N.B. Anderson, R.A. Bulatoa, R .A. \& B.Cohen (Eds.). Critical Perspectives on Racial \& Ethnic Differences in Health in Late Life.Washington, D.C.: National Research Council. 2004; 492-539.

[27] Rathore SS, Foody JM, Wang Y, Smith GL, Herrin J, Masoudi FA, et al. Race, quality of care, and outcomes of elderly patients hospitalized with heart failure. JAMA. 2003; 289(19): 2517-2524. PMid:12759323 http://dx.doi.org/10.1001/jama.289.19.2517

[28] McCullough, PA, Philbin EF, Spertus JA, Kaatz S, Sandberg KR, Weaver W.D. Confirmation of a heart failure epidemic: Findings from the resource utilization among congestive heart failure (REACH) study. Journal of the American College of Cardiology. 2002; 39: 160-9.

[29] Riedinger MS, Dracup KA, Brecht M-L, Padilla G, Sarna L. Quality of life in patients with heart failure: Do gender difference exist? Heart \& Lung. 2001; 30 (2): 105-116. http://dx.doi.org/10.1067/mhl.2001.114140

[30] Kitzman, D.W., Rich, M.W. Age disparities in heart failure research. JAMA. 2010; 304(17): 1950-1951. PMid:21045104 http://dx.doi.org/10.1001/jama.2010.1592

[31] Westlake C, Dracup K, Creaser J, Livingston N, Heywood T, Huiskes B, et al. Correlates of health-related quality of life in patients with heart failure. Issues in Cardiovascular Nursing. 2002; 31(2): 85-93.

[32] Paul S. Impact of a nurse-managed heart failure clinic: a pilot study. Am J Crit Care. 2000; 9(2): 140-6. PMid:10705427

[33] Ducharme A, Doyon O, White M, Rouleau JL, Brophy JM. Impact of care at a multidisciplinary congestive heart failure clinic: a randomized trial. Canadian Medical Association Journal. 2005; 173(1): 40-45. PMid:15997043

http://dx.doi.org/10.1503/cmaj.1041137 